\title{
Princípios JuRídicos
}

Carlos Eduardo de Freitas Fazoli*

\section{Introdução}

No atual estágio em que se encontra o estudo jurídico no Brasil, parecenos que é uma exigência técnica explorar aquilo que é fundante do Direito, que lhe é base e não decorrência, o conjunto dos princípios jurídicos que se apresenta especialmente no texto constitucional. Os princípios devem lastrear todas as atividades jurídicas, sejam interpretativas, normativas, aplicativas ou integrativas. Contudo, não é o que temos encontrado. A praxe nos mostra que os juristas não têm dado a devida importância aos princípios. Parte-se de um segundo momento, deixando-os de lado como se nada representassem para o sistema.

Assim, este trabalho tem por objetivo discorrer sobre os princípios e sua importância, já que estão na base do nosso arcabouço jurídico. Procuraremos conciliar as definições clássicas ${ }^{1}$ (infra, $n .2$ ) que os colocam em posição de destaque sob a ótica material, com a não menos clássica divisão das normas jurídicas em princípios e regras.

Neste ponto, mister uma ressalta. Toda vez que falarmos em princípio, o faremos sob o enfoque constitucional. Como a Constituição é o conjunto das normas mais importante de um sistema jurídico e está no ápice da pirâmide normativa, mutatis mutandis, devemos vislumbrar os princípios (normas fundamentais hipotéticas ou não) de forma idêntica.

\section{Dos princípios jurídicos}

\section{Breves considerações sobre os princípios}

Inicialmente, os princípios não tinham força de norma jurídica. Eram exortações de ordem moral ou política (ROTHENBURG, 2003, p.13), sugestões, idéias de direção. No Brasil, até o advento da Constituição Federal de 1988, as normas constitucionais e, a fortiori, os princípios

* Mestrando em Sistema Constitucional de Garantia de Direitos - ITE/Bauru. Especialista em Direito Civil e Direito Processual Civil - INPG/Araraquara. Professor de Direito do Centro Universitário de Araraquara - UNIARA. Procurador da Fazenda Nacional.

1. Como as de Celso Antônio Bandeira de Mello (2000) e Roque Antonio Carrazza (2002). 
jurídicos não apresentavam efetividade em função do "não reconhecimento de força normativa aos seus textos e da falta de vontade política de dar-lhes aplicabilidade direta e imediata" (BARROSO; BARCELLOS, 2003, p.142).

Com o passar do tempo e com a evolução do Direito, os princípios foram reconhecidos como verdadeiras normas com eficácia jurídica e aplicabilidade direta e imediata (BARROSO; BARCELLOS, 2003, p.149). Deixaram de ser simples orientações para se tornarem comandos dotados de efetividade e juridicidade. Comandos estes que devem ser obedecidos por todos e que servem de lastro para a satisfação imediata de direitos subjetivos.

A importância dos princípios é tão grande que Celso Antônio Bandeira de Mello (2000, p.748), em memorável passagem, afirma que a violação a um princípio é a forma mais grave de ilegalidade ou de inconstitucionalidade. Eis a citada advertência: "Violar um princípio é muito mais grave que transgredir uma norma qualquer. A desatenção ao princípio implica ofensa não apenas a um específico mandamento obrigatório, mas a todo o sistema de comandos. É a mais grave forma de ilegalidade ou inconstitucionalidade, conforme o escalão do princípio atingido, porque representa insurgência contra todo o sistema, subversão de seus valores fundamentais, contumélia irremissível a seu arcabouço lógico e corrosão de sua estrutura mestra".

Aqui precisamos fazer uma breve digressão. No ordenamento jurídico brasileiro, as normas estão hierarquicamente organizadas, respeitando-se uma relação de compatibilidade vertical. Essas normas estão dispostas na forma piramidal e a Constituição Federal se encontra no ápice. Todas as demais, localizadas em patamares inferiores, devem obediência a ela.

Ao analisarmos somente a Carta Magna, verificamos que internamente também há hierarquia em face do conteúdo valorativo, ainda que não formalmente. Na Lei Maior, os princípios estão axiologicamente em posição superior, seja pelo valor intrínseco que possuem, seja pela sua característica de base, de fundamentação, do nosso Diploma. Nessa linha de pensar, Luiz Alberto David Araujo e Vidal Serrano Nunes Júnior (2005, p.67), com pena de mestre, afirmam que "podemos falar na existência de uma hierarquia interna valorativa dentro das normas constitucionais, ficando os princípios em um plano superior, exatamente pelo caráter de regra estrutural que apresentam".

Por sua vez, Ivo Dantas (1995, p.86), ao cuidar da Constituição Federal de 1988, reconhece que "[...] a partir da consagração, pelo texto constitucional, de Princípios Fundamentais e de Princípios Gerais voltados para determinado setor, parece-nos possível estabelecer entre ambos uma nova hierarquia". ${ }^{2} \mathrm{Na}$ mesma toada, Ruy Samuel Espíndola (2003, p.82) afirma que "os princípios

2. Ivo Dantas (1995) reconhece a diferença entre princípio e norma. jurídicos como princípios constitucionais têm a mais alta normatividade do sistema jurídico".

Finalizando, o estudo dos princípios está intimamente relacionado à teoria dos valores devido à importância do seu objeto (ROTHENBURG, 2003, p.17). Na doutrina estrangeira, Joaquín Rodríguez-Toubes Muñiz (2000, p.42) assevera que, “[...] los principios pueden ser descritos como normas que persiguen la realización en la mayor medida posible de valores, entendidos éstos en sentido amplio. Los valores vienen a ser el objetivo normativo de los princípios."

\section{Definição}

O termo princípio não é de fácil definição, uma vez que pode ser utilizado em vários contextos e com diversos significados. Os autores são unânimes neste sentido. ${ }^{3}$ A Filosofia, a Sociologia e o Direito, dentre outras ciências, utilizam a palavra princípio em suas definições, cada qual sob sua ótica.

Aurélio Buarque de Holanda Ferreira (1995, p.529), em seu monumental dicionário, nos traz uma primeira definição: "Princípio. $S . m$. 1. Momento ou local ou trecho em que algo tem origem; começo. 2. Causa primária. 3. Elemento predominante na constituição de um corpo orgânico. 4. Preceito, regra, lei. 5. P.ext. Base; germe".

Ingressando na seara jurídica, transcrevemos a definição proposta por Celso Antônio Bandeira de Mello (2000, p.747-48):

"Princípio [...] é, por definição, mandamento nuclear de um sistema, verdadeiro alicerce dele, disposição fundamental que se irradia sobre diferentes normas compondo-lhes o espírito e servindo de critério para sua exata compreensão e inteligência exatamente por definir a lógica e a racionalidade do sistema normativo, no que lhe confere a tônica e lhe dá sentido harmônico".

José Afonso da Silva (2001, p.96) nos traz uma primorosa definição: "Os princípios são ordenações que se irradiam e imantam os sistemas de normas, são [como observam Gomes Canotilho e Vital Moreira] 'núcleos de condensações' nos quais confluem valores e bens constitucionais".

Ao definir princípio jurídico, Roque Antônio Carrazza (2002, p.33), mestre de todos nós, nos fornece uma definição lapidar:

"Segundo nos parece, princípio jurídico é um enunciado lógico, implícito ou explícito, que, por sua grande generalidade, ocupa posição de preeminência nos vastos quadrantes do direito e, por isso mesmo, vincula, de modo inexorável, o entendimento e a aplicação das normas jurídicas que com ele se conectam".

3. Apenas à guisa de exemplo, Joaquín Rodríguez-Toubes Muñiz (2000, p.30) e José Afonso da Silva (2001, p.95). 
Cuidando especificamente dos princípios gerais de direito, Joaquín Arce y Flórez-Valdés (1990, p.79) os definem como "[...] las ideas fundamentales sobre la organización jurídica de una comunidad, emanadas de la conciencia social, que cumplen funciones fundamentadora, interpretativa y supletoria respecto de su total ordenamiento jurídico".

Finalizando as definições doutrinárias, Ivo Dantas (1995, p.59) nos ensina que: “[...] PRINCÍPIOS são categoria lógica e, tanto quanto possível, universal, muito embora não possamos esquecer que, antes de tudo, quando incorporados a um sistema jurídico-constitucional-positivo, refletem a própria estrutura ideológica do Estado, como tal, representativa dos valores consagrados por uma determinada sociedade".

Pelo que observamos até aqui, os princípios refletem os valores mais caros de uma sociedade, sendo que um princípio jurídico-constitucional pode ser comparado a uma "norma jurídica qualificada" (CARRAZZA, 2002, p.41).

"Trata-se da expressão dos valores principais de uma dada concepção do Direito, naturalmente abstratos e abrangentes" (ROTHENBURG, 2003,p.18). Todavia, "possuem um significado determinado, passível de um satisfatório grau de concretização [...]" (ROTHENBURG, 2003, p.18), podendo ser um limite para as regras ou um conteúdo para uma norma (ROTHENBURG, 2003, p.16).

Para nós, princípio é uma norma com alto grau de abstração que expressa um valor fundamental de uma dada sociedade e, servindo de base para o ordenamento jurídico, limita as regras que se relacionam com ele, integra as lacunas normativas, serve de parâmetro para a atividade interpretativa e, por possuir eficácia, pode ser concretizado e gerar direitos subjetivos.

\section{Fases evolutivas}

Os princípios passaram por três fases marcantes, as quais merecem destaque: jusnaturalismo, positivismo e "pós-positivismo".

A partir do século XVI, com o surgimento do jusnaturalismo e com a crença na existência de um direito natural, isto é, em valores e pretensões que são inerentes ao homem independentemente da existência ou não de alguma norma oriunda do Estado, os princípios eram vistos apenas como orientações ou como objetivos a serem perseguidos. Não se falava em eficácia, aplicabilidade ou concretização. Eram apenas direcionamentos.

No século XX encontramos o positivismo jurídico onde o "direito é norma, ato emanado do Estado com caráter imperativo e força coativa" (BARROSO; BARCELLOS, 2003, p.146). Portanto, afastando-se do direito natural, os princípios somente eram encontrados nas normas formalmente emanadas do Estado. Contudo, o positivismo entrou em decadência a partir dos movimentos fascista e nazista. Nestes, diversas atrocidades foram cometidas sob o amparo de textos legais. Em um Estado legalista, tudo o que está "escrito" é válido, é adequado. Uma lei, desde que formalmente em ordem, poderia atentar diretamente contra o direito à vida ou à dignidade da pessoa humana, por exemplo. Não se vislumbrava, naquele momento histórico, uma análise do conteúdo material da norma em face dos direitos fundamentais.

Atualmente, nos deparamos com um novo movimento jurídicofilosófico que vem sendo chamado de "pós-positivismo". Joaquín Arce y Flórez-Valdés fala em "formulación neonaturalista" (2005, p.44). Luís Roberto Barroso e Ana Paulo de Barcellos (2003, p.147) definem esta nova fase com brilhantismo:

“O pós-positivismo é a designação provisória e genérica de um ideário difuso, no qual se incluem a definição das relações entre valores, princípios e regras, aspectos da chamada nova hermenêutica constitucional, e a teoria dos direitos fundamentais, edificada sobre o fundamento da dignidade humana. A valorização dos princípios, sua incorporação, explícita ou implícita, pelos textos constitucionais e o reconhecimento pela ordem jurídica de sua normatividade fazem parte desse ambiente de reaproximação entre Direito e Ética".

\section{Características dos princípios}

Os princípios, hodiernamente, apresentam as seguintes características: caráterde norma jurídica(normatividade), imperatividade, eficácia, precedência (superioridade) material (ROTHENBURG, 2003, p.17) e abstração.

Os princípios são espécie da qual as normas são gênero. Da mesma forma que as regras, possuem caráter de norma jurídica, normatividade, juridicidade.

Por serem imperativos, devem ser incondicionalmente observados. Regina Maria Macedo Ney Ferrari (2001, p.75), ao tratar das normas constitucionais, nos traz uma interessante definição sobre a sua imperatividade, a qual se aplica in totum aos princípios:

"As normas constitucionais, em virtude de sua juridicidade, apresentam como traço característico, assim, como todas as demais normas jurídicas, a sua imperatividade, ou seja, a obrigatoriedade da obediência de seus comandos por parte das pessoas às quais se dirigem, sejam estas pessoas individuais, coletivas ou os próprios órgãos do Poder Público".

Os princípios também possuem eficácia, ou seja, devem ser obedecidos em sua plenitude e a eventual inobservância pode ser reparada judicialmente. Ademais, "a eficácia é um atributo associado às normas e consiste na conseqüência jurídica que deve resultar de sua observância, podendo ser exigida judicialmente se necessária" (BARROSO; BARCELLOS, 2003, p.168).

Esta eficácia pode ser observada sob quatro aspectos: 1) eficácia positiva ou simétrica; 2) eficácia interpretativa; 3) eficácia negativa; e, 4) eficácia 
vedativa do retrocesso. A eficácia positiva é a possibilidade de se exigir judicialmente um direito subjetivo garantido por um princípio. Por sua vez, eficácia interpretativa é a necessidade de se interpretar as normas inferiores em conformidades com as superiores, lembrando-se da superioridade axiológica que os princípios possuem sobre as demais. Já a eficácia negativa determina que todas as normas ou atos que sejam incompatíveis com os princípios sejam declaradas inválidas. Finalmente, a eficácia vedativa do retrocesso está intimamente relacionada à eficácia negativa e aos princípios fundamentais, uma vez que permite que seja exigida, do Poder Judiciário, a invalidação de uma norma que revogue outra (que disciplina ou aumenta um direito fundamental) sem a respectiva substituição (ou contrapartida) (BARROSO; BARCELLOS, 2003, p.168-171).

Tendo em vista que os princípios refletem os valores supremos de uma sociedade, eles possuem precedência axiológica sobre as demais normas. Sob o ponto de vista material, há uma preeminência dos princípios sobre as regras. Mesmo entre os princípios é possível uma diferenciação valorativa.

Por derradeiro, possuem alta abstração, não trazendo em si regras de conduta, malgrado possam ser aplicados diretamente a um caso concreto.

\section{Funções dos princípios}

Mais importante do que estabelecer as características dos princípios é identificar as suas funções. Dessarte, podemos citar, entre outras, as funções normativa, integrativa e interpretativa.

Em primeiro lugar, os princípios têm função normativa. Sendo normas jurídicas, podem ser concretizados e geram direitos subjetivos. Têm, ao lado das regras, função normativa. Em segundo lugar, havendo uma lacuna jurídica, esta pode ser suprida com a utilização dos princípios ${ }^{4}$. Encontramos aqui uma clara função integrativa em face das omissões legislativas. Finalmente, em terceiro lugar, têm função interpretativa, ou seja, condicionam a atividade do intérprete. Nenhuma interpretação pode ser efetivada sem que se leve em conta os princípios jurídicos.

Podemos ainda acrescentar que os princípios diminuem a discricionariedade jurisdicional e vinculam o legislador (ROTHENBURG, 2003, p.44-45). Mas não é só. De forma ampla “[...] os princípios exercem função importantíssima dentro do ordenamento jurídico-positivo, já que orientam, condicionam e iluminam a interpretação das normas jurídicas em geral, aí incluídos os próprios mandamentos constitucionais" (SIQUEIRA JUNIOR, 2004, p.161-162).

4. Reza o art. $4^{\circ}$ da Lei de Introdução ao Código Civil: "Quando a lei for omissa, o juiz decidirá o caso de acordo com a analogia, os costumes e os princípios gerais de direito"

\section{Diferenças entre princípios e regras}

Após a exposição supra, onde tecemos considerações gerais sobre os princípios, é imperioso irmos além e apresentar as diferenças entre princípios e regras.

$A b$ initio, precisamos enfatizar que princípios e regras são espécies das quais as normas são o gênero. Esta distinção ganhou relevo a partir dos estudos desenvolvidos por Ronald Dworkin e Robert Alexy (ESPÍNDOLA, 2002, p.66), festejados mestres da atualidade jurídica. Princípios e regras são, portanto, verdadeiras normas jurídicas, com todas as conseqüências que uma afirmação desse tipo pode resultar.

Por sua vez, normas, segundo José Afonso da Silva (2001, p.95) são: “[ [...] preceitos que tutelam situações subjetivas de vantagem ou de vínculo, ou seja, reconhecem, por um lado, a pessoas ou a entidades a faculdade de realizar certos interesses por ato próprio ou exigindo ação ou abstenção de outrem, e, por outro lado, vinculam pessoas ou entidades à obrigação de submeter-se às exigências de realizar uma prestação, ação ou abstenção em favor de outrem".

Neste ponto, destacamos que as "normas não são textos nem o conjunto deles, mas os sentidos construídos a partir da interpretação sistemática dos textos normativos" (ÁVILA, 2003, p.23). ${ }^{5}$

Postas essas premissas, verificamos que os princípios possuem uma "estrutura aberta" (GUERRA, 2003, p.84), "têm maior teor de abstração e incidem sobre uma pluralidade de situações" (BARROSO; BARCELLOS 2003, p.148). Já as regras possuem uma "estrutura fechada" (GUERRA, 2003, p.84), a qual contém um mandamento e o seu respectivo conseqüente. "As regras contêm relato mais objetivo, com incidência restrita às situações às quais se dirigem" (BARROSO, BARCELLOS, 2003, p.148). Nestas, os modais deônticos obrigatório, proibido ou permitido estão sempre presentes.

Quando uma regra passa a viger, ela jamais exclui por completo um princípio que com ela se relaciona. Os princípios estão sempre abertos a novas regras que podem surgir à medida que a sociedade evolui e delas necessite. $\mathrm{O}$ fato de uma regra indicar um caminho em determinado sentido para um determinado princípio não impede que, no futuro, outra regra seja editada indicando sentido oposto ao mesmo princípio. "As regras apresentam-se, portanto, como objeto da incidência dos princípios.” (ROTHENBURG, 2003, p.40)

\section{Finalidade da classificação}

Aclassificação das normas em princípios e regras não tem uma finalidade

5. No mesmo sentido, Luís Roberto Barroso e Ana Paula de Barcellos (2003, p.155). Sobre a questão, recomendamos a leitura de Paulo de Barros Carvalho (2003). 
meramente doutrinária. Humberto Ávila (2003, p.57) relata dois motivos que justificam tal classificação:

“1) [...] antecipar características das espécies normativas de modo que $\mathrm{o}$ intérprete ou o aplicador, encontrando-as, possa ter facilitado seu processo de interpretação e aplicação do Direito. 2) [...] aliviar, na medida em que a uma qualificação das espécies normativas permite minorar - eliminar jamais - a necessidade de fundamentação, pelo menos indicando o que deve ser justificado."

Classificando-se os princípios como norma jurídica é possível justificar a sua força normativa, uma vez que estas não precisam de complemento para apresentar eficácia.

\section{regras}

\section{Critérios utilizados para a divisão das normas em princípios e}

A distinção entre regras e princípios pode se dar por vários critérios: qualitativo, pelo grau de generalidade, de abstração ou de sua fundamentalidade.

Pelo critério qualitativo, se leva em conta o conteúdo material da norma, a importância axiológica.

"Se os princípios têm suas propriedades diferenciando-se por sua natureza (qualitativamente) dos demais preceitos jurídicos, a distinção está em que constituem eles expressão primeira dos valores fundamentais expressos pelo ordenamento jurídico informando materialmente as demais normas (fornecendo a inspiração para o recheio)". (ROTHENBURG, 2003, p.16)

Através do grau de generalidade também podemos separar regras de princípios. Quanto mais genérica a norma, mais próxima ela estará de um princípio. Ao revés, quanto mais específica, quanto menos genérica, mais próxima de uma regra.

Por outro lado, há quem defenda o grau de abstração como critério para a especificidade (ÁVILA, 2003, p.167). Para tanto, não se leva em conta a diferença qualitativa, mas sim a amplitude de sua abrangência. Cabe, porém, ressaltar que "uma norma pode ser precisa em seu significado, mas genérica em seu alcance [...]" (ROTHENBURG, 2003, p.19). Justamente pelo fato de ser abrangente é que possui aplicação ampla, evoluindo sua incidência juntamente com a sociedade.

Continuando, os princípios possuem alto grau de abstração em decorrência da vagueza e da estrutura aberta que possuem, características que lhes são peculiares. Mas não são considerados indeterminados. Esta vagueza é, pois, apenas "um jeito de ser" (ROTHENBURG, 2003, p.27).

Outro critério que pode ser utilizado é o da aplicabilidade. Para quem utiliza esse critério, os princípios não seriam aplicados de per si, mas precisariam de outras normas (regras) para que pudessem ser concretizados. As regras, por sua vez, possuem menor grau de abstração e alta densidade normativa, tendo, também, a função de concretizar os princípios 6 . Assim sendo, as regras são aplicadas mecanicamente através da subsunção.

Finalmente, a separação entre princípios e regras pode ser estabelecida através de um possível conflito normativo. Melhor explicando, os conflitos entre princípios são resolvidos através das regras de ponderação (infra, n. 3.3) enquanto os conflitos entre regras devem ser tratados como verdadeiras antinomias jurídicas (infra, n. 3.4).

Luís Roberto Barroso e Ana Paula de Barcellos (2003, p.150) apresentam três critérios para distinguir princípios de regras: 1) conteúdo; 2) a estrutura normativa; 3) as particularidades da aplicação. Quanto ao conteúdo, os princípios têm por objeto valores ou fins, enquanto as regras descrevem uma conduta. No que toca à estrutura normativa, os princípios não descrevem condutas, cabendo ao intérprete estabelecer quais ações devem ser tomadas, enquanto as regras já trazem os atos a serem praticados diante de um fato preestabelecido. Os princípios são aplicados através da ponderação diante de um caso concreto, enquanto as regras se aplicam sob a forma do tudo ou nada, mediante subsunção.

\section{Colisões entre princípios}

Uma das grandes diferenças entre princípios e regras está na respectiva aplicação, ou seja, na incidência aos casos em que se vislumbrem possíveis colisões, sejam entre princípios, sejam entre regras. Os métodos a serem utilizados são diversos.

Quando dois princípios forem aplicáveis a um caso concreto, um deles deverá ceder em face do outro. Contudo, ambos permanecerão válidos e vigentes. O intérprete deverá evitar o "sacrifício" total de um dos princípios envolvidos. É muito importante ter em mente que todos os princípios aplicáveis ao caso continuam válidos e integrando o sistema jurídico. Mesmo que se pudesse imaginar uma situação hipotética onde um princípio não fosse aplicado em sua totalidade, não haveria o que se falar em exclusão do sistema. Ele continuaria válido (SILVA, 2003, p.621-622).

Nesse trilho, Thomas da Rosa de Bustamante (2002, p.156-157) nos adverte que "[...] no caso de colisão de princípios, um deles tem que ceder ao outro, porém sem que o princípio afastado seja declarado inválido ou tenha que ser criada uma cláusula de exceção".

6. Com a devida vênia daqueles que pensam em sentido contrário, não adotamos tal posição Apenas a título de exemplo, não podemos aceitar que o caput do art. $5 .^{\circ} \mathrm{da} \mathrm{CF} / 88$ precise de uma regra para que possa ser concretizado. 
De outra banda, os princípios jurídicos nunca se apresentam de forma isolada. Devem ser analisados em conjunto com outros que com ele irão interagir (CARRAZZA, 2002, p.34). Diante de um caso concreto, vários princípios são passíveis de aplicação e formam um feixe principiológico incidente sobre a questão.

Cabe ressaltar que a colisão entre princípios somente ocorre diante de um caso concreto, não sendo correto apontá-la em tese. A análise deverá ser realizada diante das situações fáticas do caso, uma vez que o "peso" atribuído a cada princípio é variável. Assim, quando um princípio entra em "choque" com outro, o intérprete deve levar em consideração o "peso", o valor, dos princípios envolvidos. Diante de cada caso concreto, o mesmo princípio pode assumir diferentes valorações.

A respectiva aplicação se dará "mediante ponderação: à vista do caso concreto, o intérprete irá aferir o peso que cada princípio deverá desempenhar na hipótese, mediante concessões recíprocas, e preservando o máximo de cada um, na medida do possível" (BARROSO; BARCELLOS, 2003, p.149). A melhor doutrina fala em ponderação, conformação ou modulação de princípios.

Assim, parece-nos preferível falar em ponderação ou em conformação a falar em colisão, embora esse último termo seja corrente na doutrina. Walter Claudius Rothenburg (2003, p.37), chega a utilizar o termo "fragmentação dos princípios" já que dois ou mais princípios podem se compor para a solução do caso concreto. Utiliza, esse mestre, também o termo "modulação" de princípios.

Desta feita, a dita "colisão" pode se dar de duas formas: positiva ou negativa. Tendo em vista o brilhantismo de Walter Claudius Rothenburg (2003, p.37), pedimos vênia para transcrever a diferença apontada pelo ilustre jurista:

"A primeira situação: há colisão de princípios quando princípios conflitantes são suscitados, devendo-se resolver com base na precedência de um ou vários em detrimento dos demais, que são episodicamente afastados; por exemplo: vida privada versus liberdade de informação. A segunda: existe concorrência de princípios quando princípios convergentes incidem sobre o caso, resolvendo-se por composição; exemplo: os princípios da moralidade e da impessoalidade inspirando a Administração Pública".

Por sua vez, a citada "modulação" (ou ponderação) deve ser regida pela proporcionalidade (ROTHENBURG, 2003, p.41). Aqui precisamos fazer um parêntese. Não devemos utilizar, in casu, a expressão "princípio" da proporcionalidade (ROTHENBURG, 2003, p.42). A proporcionalidade não é um princípio a ser ponderado juntamente com os demais. Ela se confunde, de per si, com a própria ponderação. É, pois, um caminho a ser percorrido. (GUERRA, 2003, p.91-92)

Retomando o fio da meada, segundo Marcelo Lima Guerra (2003, p.91), a regra da proporcionalidade pode ser dividida em três elementos parciais, "[...] a saber, a adequação, a necessidade e a proporcionalidade em sentido estrito". Através da adequação deve-se buscar uma perfeita pertinência entre os meios utilizados e os fins perseguidos, ou seja, aqueles devem ser idôneos A necessidade determina a utilização do meio menos gravoso, limitando-se ao “estritamente necessário". Já a proporcionalidade em sentido estrito "impõe uma avaliação global da situação, na qual faça uma correspondência jurídica entre meios e fins, no sentido de estabelecer as vantagens e desvantagens do emprego dos meios, à luz de outros fins envolvidos na questão" (GUERRA, 2003, p.92)

A ponderação, portanto, pode ser definida como "uma técnica de decisão jurídica aplicável a casos difíceis, em relação aos quais a subsunção se mostrou insuficiente, especialmente quando uma situação concreta dá ensejo à aplicação de normas de mesma hierarquia que indicam soluções diferenciadas" (BARROSO; BARCELLOS, 2003, p.153). É, pois, um método a ser utilizado na solução dos chamados hard cases.

Durante o processo de ponderação: “[...] os diferentes grupos de normas e a repercussão dos fatos do caso concreto estarão sendo examinados de forma conjunta, de modo a apurar os pesos que devem ser atribuídos aos diversos elementos em disputa e, portanto, o grupo de normas que deve preponderar no caso. Em seguida, é preciso ainda decidir quão intensamente esse grupo de normas - e a solução por ela indicada - deve prevalecer em detrimento dos demais, isto é: sendo possível graduar a intensidade da solução escolhida, cabe ainda decidir qual deve ser o grau apropriado em que a solução deve ser aplicada." (BARROSO; BARCELLOS, 2003, p.154-155)

Todas as vezes que esse processo for utilizado, a motivação é imprescindível. A argumentação jurídica apresentada pelo intérprete deverá trazer os fundamentos normativos ${ }^{7}$, a possibilidade de universalização dos critérios adotados pela decisão e utilizar os princípios instrumentais de interpretação e materiais propriamente ditos (BARROSO; BARCELLOS, 2003, p.158-159).

Finalmente, nas hipóteses onde normas constitucionais são incidentes, o intérprete deve adotar o método da ponderação em homenagem ao princípio da unidade da Constituição ${ }^{8}$.

7. E não apenas os fundamentos pessoais ou morais do intérprete.

8. Sobre o princípio da unidade da Constituição, vide Luiz Alberto David Araujo e Vidal Serrano Nunes Junior (2005, p.85-86). Segundo eles, “o princípio da unidade indica que a Constituição é um sistema integrado por diversas normas, reciprocamente implicadas, que, dessa feita, devem ser compreendidas na sua harmoniosa globalidade". 


\section{Conflitos entre regras}

Diferentemente do que ocorre com os princípios, a aplicação das regras se dá por mera subsunção. Quando estamos diante de um conflito entre duas ou mais regras, temos uma verdadeira antinomia legal. Para tanto, o intérprete deverá utilizar-se das conhecidas regras lex posterior derogat legi priori e lex speciailis derogat legi generali ${ }^{9}$.

Nessas hipóteses, uma das regras será aplicada e as demais cederão totalmente. Estas serão consideradas inválidas e, por conseguinte, afastadas do ordenamento jurídico. Ao contrário dos princípios, uma regra vale ou não vale. Não existe um "meio termo". Para as regras temos o chamado tudo ou nada (all or nothing).

Sob o ponto de vista dos valores, uma regra não pode ser considerada mais importante do que outra. Todas estão em um mesmo patamar, quando analisadas sob o prisma axiológico. Uma regra constitucional, por exemplo, não apresenta qualquer superioridade sobre outra regra igualmente constitucional.

\section{Do caráter prima facie dos princípios}

Considerando as peculiaridades apresentadas na "colisão" entre princípios, podemos afirmar que eles (os princípios) representam direitos e deveres prima facie. Melhor explicando, ao analisar um princípio isoladamente, o intérprete pode vislumbrar, em um primeiro momento, a existência de um direito. Todavia, aplicando este mesmo princípio a um caso concreto, ele poderá ceder diante de outro princípio de tal sorte que aquele direito (originalmente imaginado) não subsista mais. Destarte, falamos em caráter prima facie dos princípios. Os direitos e deveres inicialmente expressos, apesar de aparentemente aplicáveis, podem ser afastados diante de uma situação concreta.

Nesta esteira, Virgílio Afonso da Silva (2003, p.611), com maestria, nos ensina que: "[...] para se chegar a um resultado ótimo é necessário, muitas vezes, limitar a realização de um ou de ambos os princípios, fala-se que os princípios expressam deveres e direitos prima facie, que poderão revelar-se menos amplos após o sopesamento com princípios colidentes".

\section{Da aplicação direta dos princípios}

Superada a exposição sobre separação entre princípios e regras,

9. Sobre a questão do conflito de leis, recomendamos a leitura de Maria Helena Diniz (2002, p.64-84). é imprescindível ressaltarmos a possibilidade de aplicação direta dos princípios.

Ninguém duvida das dificuldades na identificação, aplicação e concretização de um direito subjetivo que decorra diretamente de um princípio. Contudo, diante das características já apresentadas (supra, n. 2.3) especialmente pelo caráter normativo que exibem, é perfeitamente possível a sua concretização independentemente da existência de uma regra. E mais, hoje é fundamental que todo operador do Direito vise à concretização dos princípios de forma direta, sem a necessidade de outras regras.

Neste sentido, Walter Claudius Rothenburg (2003, p.22) nos traz uma precisa lição: "Portanto, inclusive quando os princípios não estejam retomados e desenvolvidos por preceitos mais precisos e específicos (regras), é possível - embora dificilmente operacional - deduzir e atender diretamente pretensões com fundamento exclusivo nesses princípios jurídicos".

A partir do raciocínio de Robert Alexy, Marcelo Lima Guerra (2003, p.87) explica como se dá a aplicação dos princípios: "Desta forma se pode afirmar que um princípio comanda a realização de um fim, constituído por um valor. Nessa perspectiva, é fundamental que se perceba que tal valor, o qual representa o fim comandado pelo princípio, é de ser buscado ou realizado, obviamente, através de condutas, isto é, através de ações e omissões. Tais ações e omissões, portanto, revelam-se meios para a realização de tal fim. Tais considerações são extremamente significativas para compreender de que modo se relacionam os princípios e as regras, especialmente para perceber a possibilidade de se expressar o conteúdo dos princípios em termos de regras".

E prossegue o insigne jurista: "Assim, se através de uma normaprincípio, o ordenamento comanda (prescreve) a realização de um fim, ipso facto comanda igualmente, a adoção dos meios aptos para tanto. Consistindo tais meios, como se viu, em um conjunto de ações e omissões, prescrever ou comandar a realização de um fim, através de uma norma-princípio, implica prescrever ou comandar as respectivas ações e omissões que se revelarem meios para aquele fim". (GUERRA, 2003, p.87)

Tanto é possível a aplicação direta dos princípios que a Constituição Federal estabeleceu em seu art. $5^{\circ}, \S 1^{\circ}$, que "as normas definidoras dos direitos e garantias individuais têm aplicação imediata". Não se pode duvidar, outrossim, que diversas normas contidas nesse artigo consubstanciam-se em verdadeiros princípios, como, por exemplo, o da igualdade $\left(\mathrm{CF} \text {, art. } 5^{\circ}, \text { caput }\right)^{10}$. Com esta

10. Sobre o princípio da igualdade, recomendamos a leitura de Celso Antônio Bandeira de Mello (2003). 
previsão expressa, restou superada a posição que exigia a presença de uma lei para que tais normas fossem eficazes (GUERRA, 2003, p.83).

\section{Conclusões}

Em toda atividade jurídica, o operador do Direito deve estar atento à importância e à relevância dos princípios, mormente os constitucionais. Todos têm o dever de lutar pela sua correta aplicação, eficácia e concretização. Precisamos trazer para a praxe forense as conclusões dos estudos realizados nesta área pelos diversos autores que se debruçam sobre o tema.

Ruy Samuel Espíndola (2003, p.85), em momento de rara felicidade, afirma que "é preciso eleger a Constituição e seus princípios como grandes defensores dos mais altos valores da civilidade que desejamos, e ainda não alcançamos em concretude".

De todo o exposto, após as considerações lançadas, chegamos às seguintes conclusões:

1. Os princípios jurídicos têm por objeto os valores fundamentais de uma dada sociedade.

2. Princípio é uma norma com alto grau de abstração que expressa um valor fundamental de uma dada sociedade e, estando na base do seu ordenamento jurídico, limita as regras que com ele se relacionam, integra as lacunas legais, serve de parâmetro para a atividade interpretativa e, por possuir eficácia, pode ser concretizado e gerar direitos subjetivos

3. As idéias atuais sobre princípios estão inseridas em um movimento jurídico-filosófico chamado "pós-positivismo".

4. Os princípios possuem as seguintes características: normatividade, imperatividade, eficácia, precedência material e abstração.

5. Os princípios possuem as seguintes funções: normativa, integrativa e interpretativa.

6. Norma é o gênero da qual os princípios e as regras são espécies.

7. Os princípios possuem uma estrutura aberta e podem ser aplicados a um número indeterminado de casos, enquanto as regras possuem uma estrutura fechada com incidência determinada a situações específicas.

8. Ochamado conflito entre princípios resolve-se pelométodoponderação de valores, sem a exclusão definitiva de algum deles do ordenamento jurídico. O conflito entre regras é resolvido pelo método do "tudo ou nada" (uma regra é aplicada em sua totalidade, enquanto as demais são consideradas inválidas) e da subsunção.

9. Os princípios possuem normatividade e eficácia, podendo ser aplicados diretamente sem a necessidade de alguma regra para a sua concretização.
Em última instância, os princípios devem ser o condutor da justiça, trazendo para o mundo jurídico valores consagrados pela sociedade. Com a característica de norma estruturante e o sentido material que carregam, diferentemente de meras regras de conduta, merecem ser vistos sob o ponto de vista axiológico e permear todo o Direito.

\section{Referências:}

ARAUJO, Luiz Alberto David; NUNES JÚNIOR, Vidal Serrano. Curso de direito constitucional. 9. ed. São Paulo: Saraiva, 2005.

\section{ARCE Y FLÓREZ-VALDÉZ, Joaquin. Los principios generales del}

Derecho y su formulación constitucional. Madrid: Civitas, 1990.

ÁVILA, Humberto. Teoria dos princípios: da definição à aplicação dos princípios jurídicos. 2. ed. São Paulo: Malheiros, 2003.

BARROSO, Luís Roberto; BARCELlOS, Ana Paula de. Começo da história. A nova interpretação constitucional e o papel dos princípios no direito brasileiro. Revista de Direito Administrativo, Rio de Janeiro, v.232, p.141-176, abr./jun. 2003.

BUSTAMANTE, Thomas da Rosa de. A distinção estrutural entre princípios e regras e sua importância para a dogmática jurídica - resposta às objeções de Humberto Ávila ao modelo de Robert Alexy. Revista Trimestral de Direito Civil, Rio de Janeiro, v.12, n.3, p.153-168, out./dez. 2002.

CARRAZZA, Roque Antonio. Curso de direito constitucional tributário. 17. ed. São Paulo: Malheiros, 2002.

CARVALHO. Paulo de Barros. Curso de direito tributário. 15 ed. São Paulo: Saraiva, 2003.

DANTAS, Ivo. Princípios constitucionais e interpretação constitucional. Rio de Janeiro: Lumen Juris, 1995.

DINIZ, Maria Helena. Lei de introdução ao código civil brasileiro interpretada. 9. ed. São Paulo: Saraiva, 2002. 
ESPÍNDOLA, Ruy Samuel. Conceito de princípios constitucionais. 2. ed. São Paulo: Revista dos Tribunais, 2002.

Constituição como garantia da democracia: O papel dos princípios constitucionais. Revista de Direito Constitucional e Internacional, São Paulo, v.11, n.44, p.75-86, jul./set. 2003.

FERRARI, Regina Maria Macedo Ney. Normas constitucionais programáticas. São Paulo: Editora Revista dos Tribunais, 2001.

FERREIRA, Aurélio Buarque de Holanda. Dicionário Aurélio básico da língua Portuguesa. Rio de Janeiro: Nova Fronteira, 1995.

GUERRA, Marcelo Lima. Direitos fundamentais e a proteção do credor na execução civil. São Paulo: Editora Revista dos Tribunais, 2003.

MELLO, Celso Antônio Bandeira de. Curso de direito administrativo. 12. ed. São Paulo: Malheiros Editores, 2000.

. Conteúdo jurídico do princípio da igualdade. 3.ed. São Paulo: Malheiros Editores, 2003.

MUÑIZ, Joaquín Rodríguez-Toubes. Princípios, fines y derechos fundamentales. Madrid: Dykinson, 2000.

ROTHENBURG, Walter Claudius. Princípios constitucionais. Porto Alegre: Sergio Antonio Fabris Editor, 2003

SILVA, José Afonso da. Curso de direito constitucional positivo. 19. ed São Paulo: Malheiros, 2001.

SILVA, Virgilio Afonso da. Princípios e regras: Mitos e equívocos acerca de uma distinção. Revista Latino Americana de Estudos Constitucionais, Belo Horizonte, n.1, p.607-631, jan./jun. 2003.

SIQUEIRA JUNIOR, Paulo Hamilton. Função dos princípios constitucionais. Revista do Instituto dos Advogados de São Paulo, São Paulo, v.7, n.13, p.157-166, jan./jun. 2004
TEMER, Michel. Elementos de direito constitucional. 13. ed. São Paulo: Malheiros, 1997.

\section{Resumo:}

Os princípios jurídicos possuem conteúdo material e refletem os valores maiores de uma determinada sociedade. A evolução do Direito trouxe conteúdo axiológico aos princípios possibilitando sua distinção das meras regras de conduta. Nesse contexto, os princípios podem ser aplicados diretamente, concretizando, assim, direitos fundamentais previstos na Constituição.

\section{Palavras-chave:}

Princípios, Normas, Regras, Direito, Concretização. 